\title{
Utilizing Optimized Tools to Investigate PTM Crosstalk: Identifying Potential PTM Crosstalk of Acetylated Mitochondrial Proteins
}

\author{
Henrick Horita *, Andy Law and Kim Middleton \\ Research and Development Department, Cytoskeleton Inc., Denver, CO 80223, USA; \\ andyl@cytoskeleton.com (A.L.); kimm@cytoskeleton.com (K.M.) \\ * Correspondence: henrickh@cytoskeleton.com; Tel.: +1-(303)-322-2254
}

Received: 31 March 2018; Accepted: 19 May 2018; Published: 22 May 2018

\begin{abstract}
Post-translational modification (PTM) crosstalk is recognized as a major cell-regulatory mechanism, and studies of several proteins have validated the premise that PTMs work in concert. Previous work by our group investigated the potential PTM crosstalk on proteins in the EGFR-Ras-c-Fos axis by utilizing a comprehensive set of PTM reagents termed Signal-Seeker toolkits. In this study, these tools were used to investigate the potential PTM crosstalk that occurs in acetylated mitochondrial proteins in response to a mitochondrial stress-inducing agent hydrogen peroxide $\left(\mathrm{H}_{2} \mathrm{O}_{2}\right)$. Mitochondrial protein acetylation has been shown to participate in PTM crosstalk as exemplified by the regulation of the pyruvate dehydrogenase complex via kinase, phosphatase, acetyltransferase, and deacetylase activities. Changes in the acetylated state of mitochondrial proteins were investigated, in response to $\mathrm{H}_{2} \mathrm{O}_{2}$, using a novel anti acetyl lysine (Ac-K) antibody. Signal-Seeker PTM detection tools were used to validate the acetylation state of ten mitochondrial targets, as well as their endogenous acetylation state in response to $\mathrm{H}_{2} \mathrm{O}_{2}$. Importantly, the endogenous acetylation, ubiquitination, SUMOylation 2/3, and tyrosine phosphorylation state of four target mitochondrial proteins were also investigated with the toolkit. Each of the four proteins had unique PTM profiles, but diverging acetylation and ubiquitin or SUMO 2/3 signals appeared to be a common theme. This proof-of-concept study identifies the Signal-Seeker toolkits as a useful tool to investigate potential PTM crosstalk.
\end{abstract}

Keywords: post-translational modification; acetylation; ubiquitination; SUMOylation; PTM crosstalk; mitochondria acetylation; PDHA1; IDI1; ATIC; PDHB

\section{Introduction}

Post-translational modifications (PTMs) are dynamic, tightly-regulated alterations to a protein that control the protein's structure, spatial localization, and interactions; thereby, governing its function [1-3]. Well-studied PTMs include, acetylation (Ac), ubiquitination (Ub), small ubiquitin-like modifier 2/3 (SUMOylation 2/3 (SUMO 2/3)), and tyrosine phosphorylation (pY), but there are many others [4-8]. Unbiased approaches such as mass spectrometry (MS)-proteomics have championed the growth of the PTM field by unveiling the vast abundance of PTM targets [9]. Individual PTMs, and importantly, combinations of PTMs (i.e., PTM crosstalk) increase the number of unique proteoforms from roughly 30,000 to potentially millions [10,11]. PTM crosstalk is recognized as a major cell regulatory mechanism [12,13], and extensive molecular studies of well-characterized proteins like p53, tau, and tubulin have validated the premise that PTMs work in concert to regulate these protein's functions [14-16]. The idea of PTMs working together to alter the protein's regulation and function was popularized by the epigenetic field, and termed the histone code [17]. Recent PTM studies of 
other protein targets further support the hypothesis of both positive and negative PTM crosstalk as regulatory mechanisms [18-21]. As investigators continue to decipher the role that PTMs play in regulating their target protein of interest, it will be paramount to characterize the temporal regulation and interplay of PTMs and their crosstalk.

While it is becoming clear that PTM crosstalk constitutes a major regulatory mechanism for protein function, mass spectrometry approaches [22-25], employed to identify potentially important quantitative PTM changes on any given protein/pathway, are highly specialized and not yet readily available to most labs. We have previously reported a simple approach that allows non-PTM specialists to take a snapshot of potential roles of PTMs in their system [26-28]. The Signal-Seeker toolset utilizes powerful affinity reagents for a range of common PTMs including Ac, pY, SUMO 2/3 and Ub, along with a universal lysis buffer that allows simultaneous analysis of these PTMs from a single lysate [28]. PTMs are detected using Western blot analysis, offering a quick, sensitive and easy way to determine if PTMs or PTM crosstalk could play a role in the regulation of any protein/system of interest.

This report applies the Signal-Seeker technology to study potential crosstalk between acetylation and other PTMs in mitochondria. Mitochondrial protein acetylation has been shown to participate in PTM crosstalk as exemplified by the regulation of the pyruvate dehydrogenase complex via kinase, phosphatase, acetyltransferase, and deacetylase activities [29]. Changes in the acetylated state of mitochondrial proteins were investigated, in response to hydrogen peroxide $\left(\mathrm{H}_{2} \mathrm{O}_{2}\right)$ stimulation, using a novel anti acetyl lysine (Ac-K) antibody. Signal-Seeker PTM detection tools were used to detect acetylation of the mitochondrial protein, PDHA1, as well as changes to its endogenous acetylation state in response to $\mathrm{H}_{2} \mathrm{O}_{2}$, which tracked with mitochondrial acetylation changes observed by IF. These PTM detection tools were also used to examine PDHA1 Ub, pY, and SUMO 2/3, and an increase in PDHA1 $\mathrm{Ub}$ was observed concomitantly with the decreased acetylation in response to $\mathrm{H}_{2} \mathrm{O}_{2}$. Preliminary proteomic studies identified an array of acetylated mitochondrial protein targets immunoprecipitated with the Ac-K antibody, and validation of 10 key targets were performed with Signal-Seeker PTM detection methodologies. Changes in acetylation in response to $\mathrm{H}_{2} \mathrm{O}_{2}$ for the 10 targets were also examined. Finally, crosstalk of Ac, Ub, SUMO 2/3, and pY modifications were analyzed for 4 of these mitochondrial targets. This proof-of-concept study highlights the simplicity and power of the Signal-Seeker toolkit to allow non-PTM/proteomics specialists to gain great insight into how/if PTMs may be affecting their protein/system of interest.

\section{Materials and Methods}

\subsection{Cell Culture and Reagents}

A431 human epidermoid carcinoma cells and 3T3-swiss mouse fibroblast cells were obtained from ATCC. Cells were grown in DMEM media (ATCC, Manassas, VA, USA) supplemented with $10 \%$ FBS (Atlas Biologicals, Fort Collins, CO, USA) and penicillin/streptomycin (ThermoFisher, Waltham, MA, USA). TrypLE Express was obtained from Gibco (ThermoFisher, Waltham, MA, USA). Unless otherwise noted, chemicals were obtained from Sigma Chemical Co. (Sigma, St. Louis, MO, USA). For all Western blot and IP analysis experiments, A431 cells at $60 \%$ confluency, post 5 days of cell passage, were treated with $100 \mu \mathrm{M} \mathrm{H}_{2} \mathrm{O}_{2}$ for $2 \mathrm{~h}$ in individual $15 \mathrm{~cm}$ dishes (Corning, Corning, NY, USA).

\subsection{Immunization of Mice}

AAC03 was generated using a traditional immunization method. Briefly, six-week-old BALB/c mice (Envigo, Indianapolis, IN, USA) were injected intraperitoneally with $50 \mu \mathrm{g}$ of a proprietary mixture of acetylated proteins emulsified in complete Freund's adjuvant (ThermoFisher, Waltham, MA, USA). Three subsequent injections were performed at 3 weeks intervals with the same mixture of acetylated proteins in incomplete Freund's adjuvant. Splenocytes were collected and fused with P3X63Ag8.653 mouse myeloma cells (ATCC, Manassas, VA, USA) using polyethylene glycol 1500 (PEG 1500, ATCC, Manassas, VA, USA). Hybridoma supernatants were screened by ELISA, 
and positive wells were subcloned by limiting dilution and single-cell selection. AAC02 was generated using a repetitive immunization method. Six-week-old BALB/c mice (Envigo, Indianapolis, IN, USA) were injected subcutaneously with $20 \mu \mathrm{g}$ of a proprietary mixture of acetylated proteins emulsified in complete Freund's adjuvant and RIBI (Sigma, St. Louis, MO, USA). Five subsequent injections were performed with the same mixture of acetylated proteins in incomplete Freund's adjuvant and RIBI. Antibody producing cells were collected and fused with P3X63Ag8.653 mouse myeloma cells using PEG 1500. Hybridoma supernatants were screened by ELISA, and positive wells were subcloned by limiting dilution and single-cell selection.

\subsection{Western Blotting}

A431 cells, treated or untreated with $100 \mu \mathrm{M} \mathrm{H} \mathrm{H}_{2} \mathrm{O}_{2}$, were lysed with ice-cold BlastR lysis buffer containing a cocktail of Trichostatin A (TSA) $(1 \mu \mathrm{M})$, nicotinamide $(16.5 \mathrm{mM})$, and protease inhibitors (PIC02), or n-ethylmaelimide (NEM) or Sodium Orthovanadate $\left(\mathrm{Na}_{3} \mathrm{VO}_{4}\right)$. BlastR lysis buffer is a complete cell lysis reagent that is comprised of a proprietary mixture of detergents, salts, and other buffer additives. DNA was removed by passing the lysate through the compressible BlastR filter system (Cytoskeleton, Denver, CO, USA). After dilution with BlastR dilution buffer, protein concentrations were determined with Precision Red Advanced protein reagent (Cytoskeleton, Denver, CO, USA), and measured at $600 \mathrm{~nm}$ OD. Protein lysate samples were separated using Tris-glycine SDS-polyacrylamide gel electrophoresis (ThermoFisher, Waltham, MA, USA) and transferred to Immobilon- P membranes (Millipore, Burlington, MA, USA). Membranes were blocked for $30 \mathrm{~min}$ at room temperature in Tris-buffered saline (10 mM Tris- $\mathrm{HCl}, \mathrm{pH} 8.0,150 \mathrm{mM} \mathrm{NaCl})$ containing $0.05 \%$ Tween-20 (TTBS) and 5\% milk (Thrive Life, American Fork, UT, USA), and then incubated with 0-2.5\% milk in TTBS solution containing primary antibodies for $1-2 \mathrm{~h}$ at room temperature (RT). Membranes were washed in TTBS $3 \times 10 \mathrm{~min}$, prior to secondary antibody for $1 \mathrm{~h}$ at RT. Bound antibodies were visualized with horseradish peroxidase-coupled secondary antibodies and chemiluminescent reagent (Cytoskeleton, Denver, CO, USA) according to the manufacturer's directions. Antibodies used: PDHA1 (18068-1-AP; 1:1000, Proteintech, Rosemont, IL, USA), PDHB (14744-1-AP; 1:1000, Proteintech, IL), PRDX2 (10545-2-AP; 1:1000, Proteintech, IL), IDI1 (11166-2-AP; 1:1000, Proteintech, IL), MRPL24 (16224-1-AP; 1:1000, Proteintech, IL), DTYMK (15360-1-AP; 1:500, Proteintech, IL), Hexokinase 2 (22029-1-AP; 1:1000, Proteintech, IL), SSBP1 (12212-1-AP; 1:500, Proteintech, IL), DLD (16431-1-AP; 1:500, Proteintech, IL), ALDH9A1 (26621-1-AP; 1:1000, Proteintech, IL), ATIC (A304-271A; 1:1000, Bethyl Laboratories, Montgomery, TX, USA), and HRP-anti-rabbit secondary (1:10,000; Jackson ImmunoResearch, West Grove, PA, USA). Changes were quantitated by densitometry using Image J software (rsb.info.nih.gov).

\subsection{Immunoprecipitation (IP) Assay}

A431 cells, treated or untreated with $100 \mu \mathrm{M} \mathrm{H}_{2} \mathrm{O}_{2}$, were lysed with ice-cold BlastR lysis buffer containing a cocktail of TSA $(1 \mu \mathrm{M})$, nicotinamide $(16.5 \mathrm{mM})$, and PIC02, or NEM or $\mathrm{Na}_{3} \mathrm{VO}_{4}$. DNA was removed by passing the lysate through the BlastR filter system (Cytoskeleton, Denver, CO, USA). After dilution with BlastR dilution buffer, protein concentrations were determined with Precision Red Advanced protein reagent (Cytoskeleton, Denver, CO, USA), and measured at $60 \mathrm{~m}$ OD. Samples were immunoprecipitated, using Signal-Seeker kits, with equal protein concentration and IP volumes according to the manufacturer's protocol (Cytoskeleton, Denver, CO, USA). The recommended amount of pY (30 $\mu \mathrm{L} / \mathrm{g}$ lysate; APY03-beads), Ub (20 $\mu \mathrm{L} / \mathrm{g}$ lysate; UBA01-beads), SUMO 2/3 (40 $\mu \mathrm{L} / \mathrm{g}$ lysate; ASM24-beads), Ac (50 $\mu \mathrm{L} / \mathrm{g}$ lysate; AAC04-beads), Acetyl-lysine IgG control beads ( $50 \mu \mathrm{L} / \mathrm{g}$ lysate; CIG02-beads), IgG control beads (30-40 $\mu \mathrm{L} / \mathrm{g}$ lysate; CIG01-beads), or Ub control beads ( $20 \mu \mathrm{L} / \mathrm{g}$ lysate; CUB01-beads) were added to the respective samples for $1-2 \mathrm{~h}$ and rotated at $4{ }^{\circ} \mathrm{C}$. After incubation, the affinity beads from each sample were pelleted and washed $3 X$ with BlastR wash buffer. Bound proteins were eluted using bead elution buffer (Cytoskeleton, Denver, CO, USA) and processed by Western immunoblotting. 


\subsection{Immunofluorescence (IF) Assay}

Swiss 3T3 cells were seeded on glass coverslips for at least $24 \mathrm{~h}$ before treatment. Swiss 3T3 cells were either untreated or treated with $1 \mu \mathrm{M}$ of TSA for $6 \mathrm{~h}$. Competition experiments were performed by adding $10 \mu \mathrm{g} / \mathrm{mL}$ of acetylated BSA to the AAC02 and AAC03 antibody incubation step. Organelle co-localization experiments were performed by addition of $10 \mathrm{M}$ Mitotracker orange (Thermofisher, Waltham, MA, USA) to cells for 30 min prior to fixation, or co-staining with LAMP-1 antibody (Abcam, Cambridge, MA, USA). Dynamic mitochondrial acetylation experiments were performed by treating A431 cells with $100 \mu \mathrm{M}$ of $\mathrm{H}_{2} \mathrm{O}_{2}$ for 2,6 , and $24 \mathrm{~h}$.

After respective treatments, cells were washed with 1xPBS and fixed with $4 \%$ formaldehyde for $10 \mathrm{~min}$ followed by permeabilization with $0.5 \%$ Triton X-100 for $15 \mathrm{~min}$. Cells were then blocked with $2 \%$ BSA/PBST /5\% normal goat serum for $30 \mathrm{~min}$. Cells were incubated with acetylation antibodies (AAC02; 1:1000, Cytoskeleton Inc., Denver, CO, USA) or (AAC03; 1:1000, Cytoskeleton Inc., Denver, CO, USA), or lysosomal marker LAMP 1 (ab24170; 1:100, Abcam, Cambridge, MA, USA) that were diluted with $2 \%$ BSA/PBST and incubated on fixed cells for $1 \mathrm{~h}$. Acetylation signals and lysosomal signals were visualized with goat anti-mouse Alexa 488 (1:1000) and goat anti-rabbit Alexa 555 (1:1000) respectively (Thermofisher, Waltham, MA, USA). Cells were incubated with DAPI stain for 5 min and washed three times with 1xPBS. Coverslips were mounted on slides (Thermofisher, Waltham, MA, USA) using Fluro-Gel mounting media (Electron Microscopy Sciences, Hatfield, PA, USA).

Images were acquired with a Nikon $100 \times / 1.30$ Plan Fluor objective lens on a Nikon Eclipse E600 microscope. For each antibody labeling condition, the image acquisition settings were kept the same between different experiments. The brightness, contrast, and levels of the images were adjusted and compiled using Image (NIH) software (v. 1.41, National Institutes of Health, Bethesda, MD, USA, https:/ /imagej.nih.gov/ij/index.html). No additional digital image processing was performed.

\section{Results}

\subsection{Immunofluorescence Detection of Dynamic Changes in Mitochondrial Acetylation in Response to $\mathrm{H}_{2} \mathrm{O}_{2}$}

With the recent growth in Ac targets that span well beyond epigenetic regulation [30], there has been an increased demand for additional Ac research tools. To characterize and identify unique Ac targets and/or cellular functions, two pan-acetyl-lysine monoclonal antibodies (AAC02 and AAC03) were developed by immunizing mice with a mixture of acetylated proteins. While validating these tools for IF applications it was noted that AAC03 identified histones and acetylated tubulin in response to TSA treatment (Figure 1A), which is similar to other pan-acetyl-lysine antibodies. Surprisingly, AAC02 had a unique IF profile that appeared to identify proteins in vesicular or mitochondrial structures (Figure 1A). Proteins in the mitochondria, in particular, are highly acetylated [31]; thus, it was of interest to determine if AAC02 could track the Ac state of mitochondrial proteins by IF, which was not possible with the current group of commercial pan-acetyl lysine antibodies. IF assays were performed on 3T3 cells that were co-stained with AAC02 and a mitochondria marker, mitotracker; alternatively, 3 T3 cells were co-stained with AAC02 and the vesicle marker, LAMP1 (Figure 1B). The data in Figure 1B shows convincing co-localization of AAC02 and mitochondrial structures, but minimal overlap with vesicles. While this data suggests that AAC02 identifies acetylated mitochondria proteins, it does not determine whether AAC02 can detect dynamic and physiologic changes of acetylated proteins in the mitochondria. To address this question, A431 cells were treated with $\mathrm{H}_{2} \mathrm{O}_{2}$, an oxidative agent that has been shown to regulate the mitochondrial de-acetylase, sirtuin 3 (SIRT3) [32]. Data in Figure 1C shows a pronounced decrease in mitochondrial acetylation staining with minimal changes in mitotracker staining at 2-h of treatment with $\mathrm{H}_{2} \mathrm{O}_{2}$, as well as subsequent recovery of the acetylation signal at later time-points. Collectively, these data suggest that AAC02 may be a useful tool for tracking changes in acetylated mitochondria by IF. 

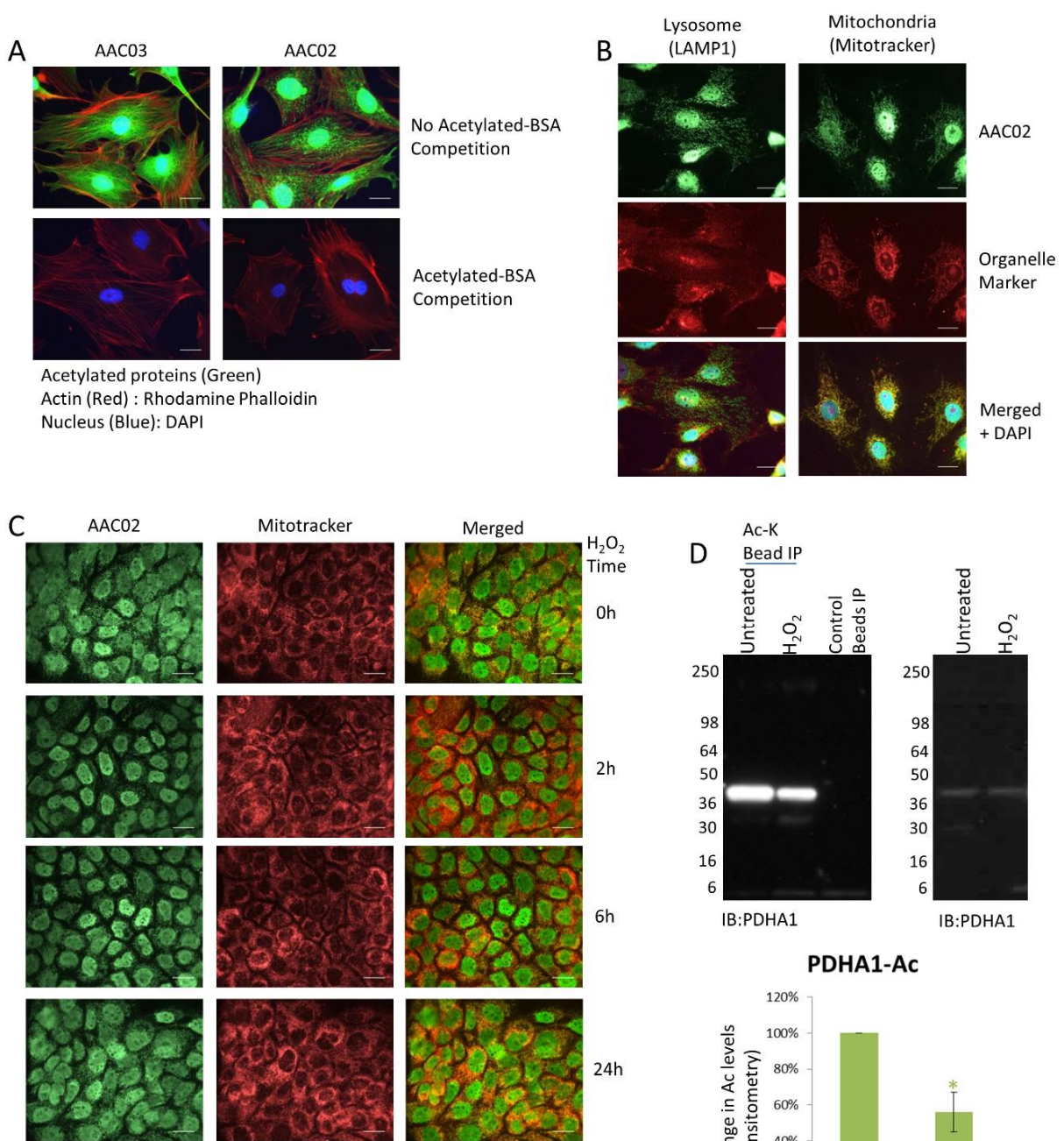

Acetylated proteins (Green)

Mitochondria (Red) : Mitotracker

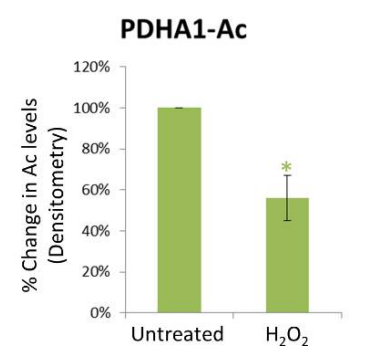

Figure 1. Ac-K Antibody, AAC02, detects dynamic changes in acetylated mitochondrial protein by IF. (A) Representative examples of TSA treated Swiss 3T3 cells stained with the Ac-K antibodies AAC02 or AAC03. Competition experiments (bottom panels) were performed by adding $10 \mu \mathrm{g} / \mathrm{mL}$ of acetylated BSA to the AAC02 and AAC03 antibody incubation step. Bars $=10 \mu \mathrm{m}($ B) Representative examples of untreated Swiss 3T3 cells co-labeled with AAC02 and a mitochondria marker (mitotracker) or AAC02 and a lysosomal marker (LAMP-1). Bars $=10 \mu \mathrm{m}$ (C) Representative examples of A431 cells co-labeled AAC02 and mitotracker. The mitochondrial acetylation state of A431 cells was measured after treatment with $100 \mu \mathrm{M}$ of $\mathrm{H}_{2} \mathrm{O}_{2}$ for $0,2,6$, and $24 \mathrm{~h}$. Bars $=10 \mu \mathrm{m}$ (D) A431 cells either untreated or treated with $\mathrm{H}_{2} \mathrm{O}_{2}$ for $2 \mathrm{~h}$ were lysed with BlastR lysis buffer. IP of acetylated proteins from $800 \mu \mathrm{g}$ of lysate were performed using Ac-K Affinity beads or Acetyl-lysine IgG control beads. Western blots, on eluted proteins, were performed with a PDHA1 antibody. Shown are representative Acetylation IP (left) and whole cell lysate (WCL) (right) Westerns from $N \geq 3$ independent experiments. Quantification of background subtracted densitometric analysis of PDHA1 acetylation is shown. Error bars represent s.e.m. $t$-test statistical analysis was performed. ${ }^{*} p<0.05$.

\subsection{PDHA1 Exhibits Diverging Changes in Acetylation and Ubiquitination in Response to $\mathrm{H}_{2} \mathrm{O}_{2}$}

To identify potential acetylated mitochondrial proteins recognized by AAC02, literature searches were performed and a promising target, pyruvate dehydrogenase E1 alpha 1 subunit (PDHA1), was identified [33]. PDHA1 was chosen because it is an acetylated mitochondrial protein that is dynamically regulated by de-acetylases [33]. Endogenous PDHA1 Ac was investigated using the 
Signal-Seeker PTM detection tool. Results in Figure 1D show that PDHA1 is highly acetylated under basal conditions, and in response to $2 \mathrm{~h}$ of $\mathrm{H}_{2} \mathrm{O}_{2}$ treatment, its acetylation state is reduced by $44 \%$. These findings correlate with the decrease in mitochondrial acetylation observed in Figure $1 \mathrm{C}$ at $2 \mathrm{~h}$ and implicate PDHA1 as an acetylated mitochondrial target that is recognized by AAC02.

$\mathrm{H}_{2} \mathrm{O}_{2}$ is a broad cell stress inducing agent that can regulate cell processes such as kinase signaling [34] and does not exclusively regulate Ac; thus, it was possible that it may be activating additional PTMs on PDHA1. The Signal-Seeker tool allows investigators to look beyond single PTMs and examine potential PTM crosstalk of a target protein [28]; therefore it was used to determine if alternative PTMs were also activated on PDHA1 in response to $\mathrm{H}_{2} \mathrm{O}_{2}$. Endogenous $\mathrm{Ub}, \mathrm{SUMO} 2 / 3$ and pY modifications of PDHA1 were investigated in response to $\mathrm{H}_{2} \mathrm{O}_{2}$ in parallel with Ac (Figure 2). The data shows that $\mathrm{H}_{2} \mathrm{O}_{2}$ does not affect the SUMO 2/3 or pY state of PDHA1 (Figure 2C,D), however PDHA1 $\mathrm{Ub}$ increased by 53\% after $2 \mathrm{~h}$ of treatment (Figure 2B). It is important to note that the percentage of total PDHA1 that is acetylated $(6.08 \%$ and $3.649 \%)$ is significantly higher than the percentage of ubiquitinated PDHA1 $(0.126 \%$ and $0.186 \%)$ (Figure $2 \mathrm{~F})$. Nevertheless, the data indicates that multiple PTMs of PDHA1 are simultaneously changing in response to $\mathrm{H}_{2} \mathrm{O}_{2}$ and provides an avenue of further investigation to decipher if these modifications of PDHA1 regulate each other.
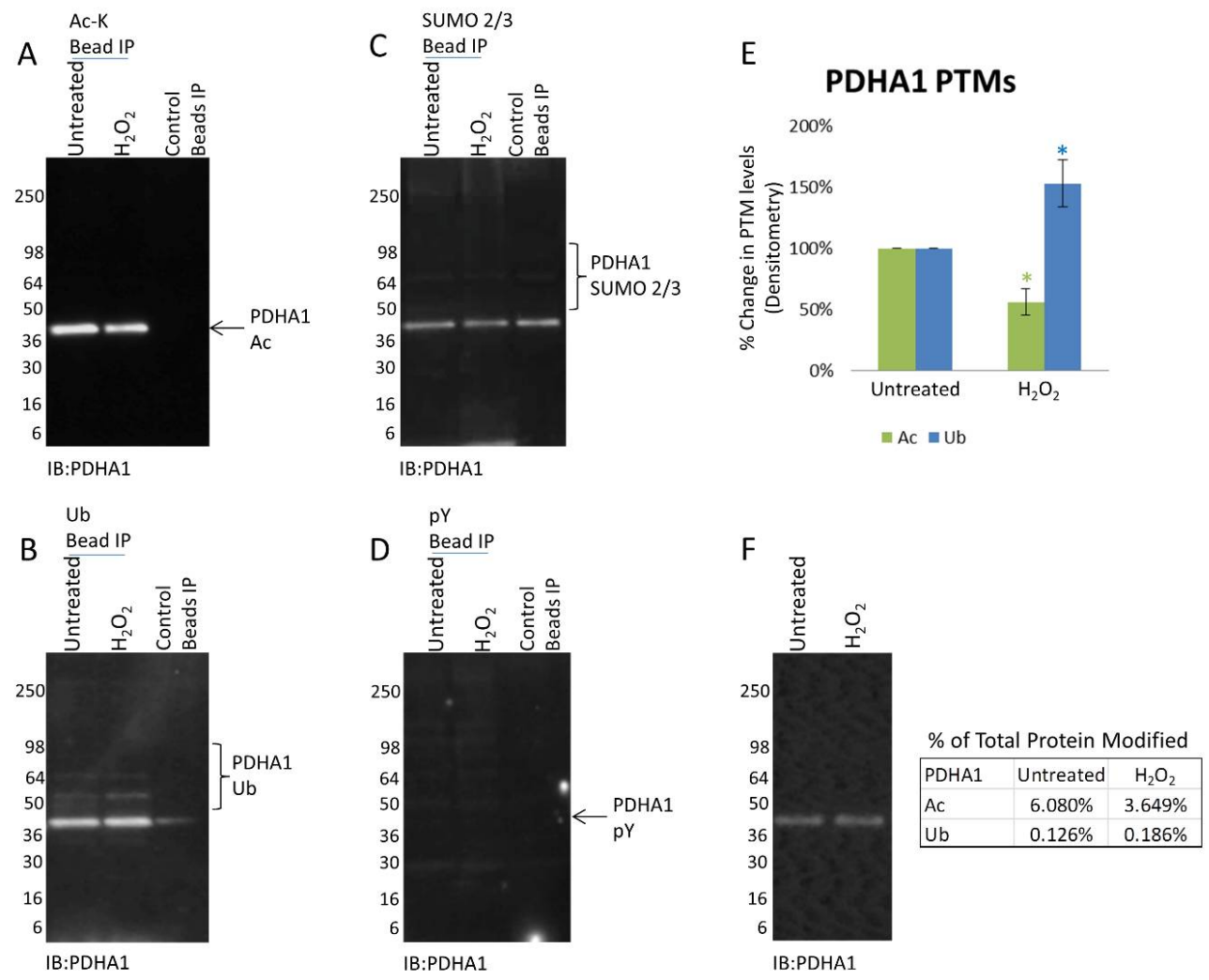

Figure 2. $\mathrm{H}_{2} \mathrm{O}_{2}$ induced $\mathrm{Ac}, \mathrm{Ub}, \mathrm{SUMO} 2 / 3$, and pY modifications of PDHA1. A431 cells either untreated or treated with $\mathrm{H}_{2} \mathrm{O}_{2}$ for $2 \mathrm{~h}$ were lysed with BlastR lysis buffer. Untreated and treated A431 lysates were incubated with (A) Ac-K beads to IP acetylated proteins and analyzed for acetylated PDHA1, (B) Ub beads to IP ubiquitinated proteins and analyzed for ubiquitinated PDHA1, (C) SUMO 2/3 beads to IP SUMOylated 2/3 proteins and analyzed for SUMO 2/3 modified PDHA1, (D) and pY beads to IP tyrosine phosphorylated proteins and analyzed for tyrosine phosphorylated PDHA1. All IPs were performed with appropriate control beads to detect non-specific detection. Shown are representative Westerns from $N \geq 3$ independent experiments. (E) Quantification of background subtracted densitometric analysis of PDHA1 PTMs. Error bars represent s.e.m. $t$-test statistical analysis was performed. ${ }^{*} p<0.05$. (F) WCL was analyzed for PDHA1 levels. The percentage of PTM modified PDHA1 relative to the total PDHA1 levels for each modification is shown. 


\section{3. $\mathrm{H}_{2} \mathrm{O}_{2}$ Treatment Results in the Deacetylation of Multiple Mitochondrial Proteins}

To further validate the utility of the Signal-Seeker toolkits in identifying acetylated proteins in this system we used mass spectrometry (MS) to identify proteins that were immunoprecipitated using Signal-Seeker AAC02 acetyl lysine affinity beads. In this case, MS was not performed to identify specific acetylation sites as we did not IP acetylated peptides, rather whole proteins were immunoprecipitated followed by trypsin digestion for MS analysis. This low sensitivity strategy was employed to allow us to maximize the chances of identifying the Signal-Seeker protein targets as multiple peptides would be generated per target protein. These preliminary studies identified 1196 protein targets and over 200 mitochondrial proteins that were predicted to be acetylated (Supplementary File S1). Additional replicates are necessary before complete analysis and reporting on these findings are possible; however, ten mitochondrial targets were randomly chosen for further validation (Table 1).

Table 1. Mitochondrial Target Proteins.

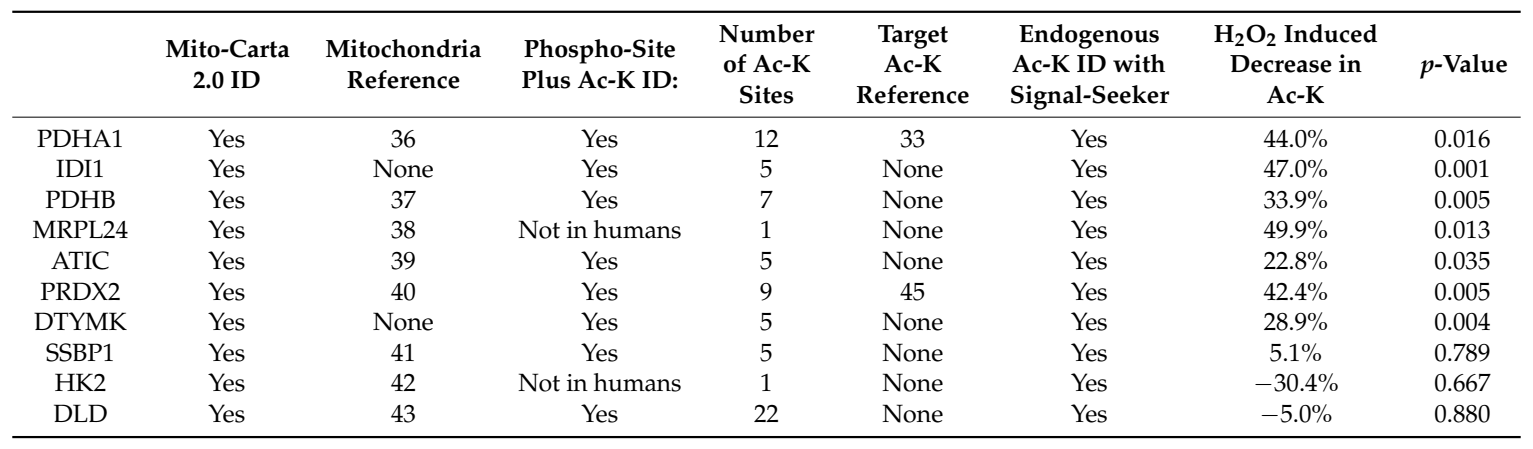

The ten protein targets were all predicted to have mitochondria localization according to the mitocarta 2.0 database [35] and 8 have been validated as mitochondrial localized [36-43] (Table 1). The majority of these proteins had been previously identified as acetylated by mass spectrometry [44]. Only PDHA1 and peroxiredoxin 2 (PRDX2) have previously been validated as acetylated by conventional methods [33,45]. The Signal-Seeker acetyl-lysine enrichment tool was used in conjunction with Western blot analysis to further validate that the ten mitochondrial targets were endogenously acetylated. As predicted, all 10 proteins were confirmed to be acetylated (Figure 3 and Figure S1). Additionally, the data presented here identified acetylation of mitochondrial ribosomal protein L24 (MRPL24) and hexokinase 2 (HK2) in human samples, which had not been detected previously (Figure 3B and Figure S1). Importantly, endogenous changes in the acetylated state of these 10 proteins in response to $\mathrm{H}_{2} \mathrm{O}_{2}$ were also investigated to determine if the Western data for these targets correlate with the IF results and to identify subjects for potential PTM crosstalk in response to $\mathrm{H}_{2} \mathrm{O}_{2}$. Data in Figure 3 shows pyruvate dehydrogenase E1 beta subunit (PDHB), MRPL24, and isopentenyl-diphosphate delta isomerase 1 (IDI1) acetylation state decreases in response to $\mathrm{H}_{2} \mathrm{O}_{2}$ by $33.9 \%, 49.9 \%$ and $47 \%$ respectively. $\mathrm{H}_{2} \mathrm{O}_{2}$-induced changes for all target proteins are shown in Table 1 . Importantly, the data shows that a majority of the targets (70\%) had significantly decreased acetylation states in response to $\mathrm{H}_{2} \mathrm{O}_{2}$. Collectively, these findings support the premise that AAC02 effectively detects changes in mitochondrial protein acetylation in both IF and IP applications, and that semi-quantitative changes in the PTM status of endogenous protein targets can be observed using Signal-Seeker tools and standard Western blot techniques. 


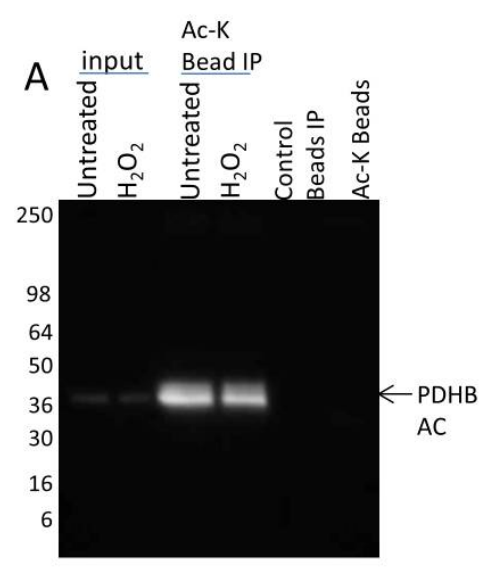

IB:PDHB

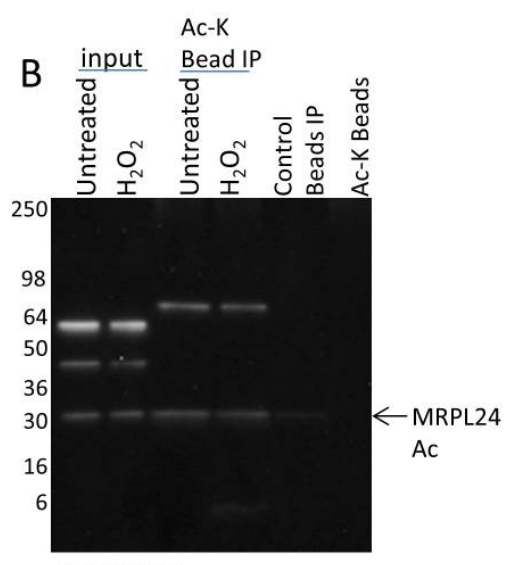

IB:MRPL24

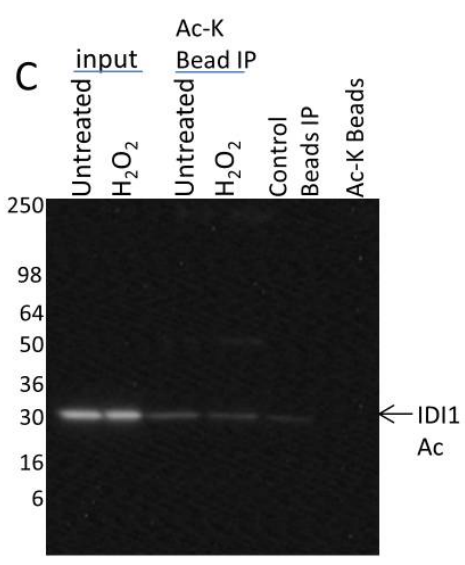

IB:IDI-1
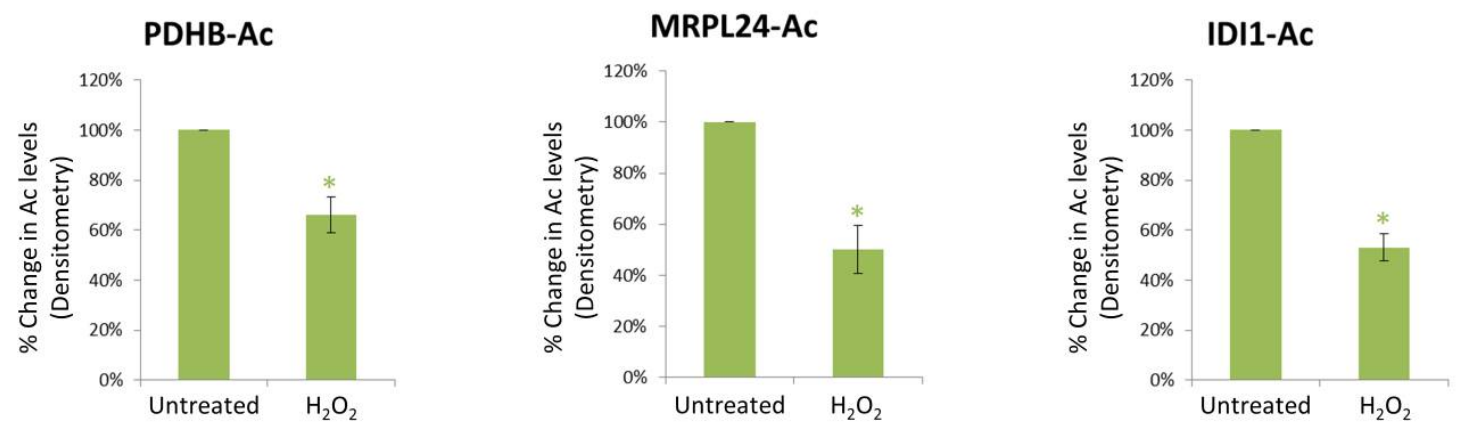

Figure 3. Endogenous acetylation of PDHB, MRPL24, and IDI1. A431 cells either untreated or treated with $\mathrm{H}_{2} \mathrm{O}_{2}$ for $2 \mathrm{~h}$ were lysed with BlastR lysis buffer. IP of acetylated proteins from $800 \mu \mathrm{g}^{-1} \mathrm{mg}$ of lysate were performed using Ac-K Affinity beads or Acetyl-lysine IgG control beads. Eluted proteins were resolved in an SDS-PAGE gel and then transferred to a PVDF membrane. Western blots were performed with (A) PDHB, (B) MRPL24, and (C) IDI1 antibodies. Shown are representative Westerns from $N \geq 3$ independent experiments. Quantification of background subtracted densitometric analysis of the three proteins is shown. Error bars represent s.e.m. $t$-test statistical analysis was performed. $* p<0.05$.

\subsection{Mitochondrial Proteins Exhibit Protein Specific PTM Changes in Response to $\mathrm{H}_{2} \mathrm{O}_{2}$}

Several of the mitochondrial proteins that exhibited decreased acetylation in response to $\mathrm{H}_{2} \mathrm{O}_{2}$ were further examined to assess their potential for PTM crosstalk. Utilizing the Signal-Seeker toolkit, $\mathrm{pY}, \mathrm{Ub}$, and SUMO 2/3 modifications were investigated and a summary of the results are reported in Table 2. Data in Figure 4 provides a snapshot of the PTM profile of IDI1 in response to $\mathrm{H}_{2} \mathrm{O}_{2}$ treatment. Analogous to PDHA1, IDI1 Ub increased (30.3\%) in response to $\mathrm{H}_{2} \mathrm{O}_{2}$ while its Ac state decreased (47\%) over the $2 \mathrm{~h}$ treatment period (Figure 4A,B). However, while $\mathrm{pY}$ of PDHA1 was not detected, pY of IDI1 was present in untreated cells, and significantly decreased (65.1\%) in response to $\mathrm{H}_{2} \mathrm{O}_{2}$ (Figure 4D). In the case of IDI 1 , its Ac $(0.596 \%$ and $0.312 \%), \mathrm{Ub}(0.326 \%$ and $0.426 \%)$, and $\mathrm{pY}(0.572 \%$ and $0.210 \%)$ state appear to represent a similar percentage of the total IDI1 protein levels. To our knowledge, this is the first endogenous validation of these PTMs and, importantly, the first report showing that the IDI1 PTM levels change in a potentially coordinated manner in response to a given treatment. Another target, $\mathrm{PDHB}$ showed a distinct increase in SUMO 2/3 modification, and a trend towards increased $\mathrm{Ub}$ in response to $\mathrm{H}_{2} \mathrm{O}_{2}$ (Figure S2). The final target, 5-aminoimidazole-4-carboxamide ribonucleotide formyltransferase /IMP cyclohydrolase (ATIC), displayed an increase in SUMO 2/3 while no Ub was detected for the protein (Figure S3). These findings highlight the prevalence of PTMs on mitochondrial target proteins, and their potential for crosstalk. 
Table 2. PTM crosstalk for Mitochondrial Targets.

\begin{tabular}{cccccc}
\hline & Signal-Seeker ID & Ac-K & Ub & SUMO 2/3 & pY \\
\hline \multirow{2}{*}{ PDHA1 } & Endogenous ID & Yes & Yes & No & No \\
& Response to $\mathrm{H}_{2} \mathrm{O}_{2}$ & $\downarrow 35.8 \%$ & $\uparrow 53 \%$ & $\mathrm{n} / \mathrm{a}$ & $\mathrm{n} / \mathrm{a}$ \\
IDI1 & Endogenous ID & Yes & Yes & No & Yes \\
& Response to $\mathrm{H}_{2} \mathrm{O}_{2}$ & $\downarrow 47.0 \%$ & $\uparrow 30.3 \%$ & $\mathrm{n} / \mathrm{a}$ & $65.10 \%$ \\
\multirow{2}{*}{ ATIC } & Endogenous ID & Yes & No & Yes & Yes \\
& Response to $\mathrm{H}_{2} \mathrm{O}_{2}$ & $\downarrow 22.8 \%$ & $\mathrm{n} / \mathrm{a}$ & $\uparrow 36.9 \%$ & No Change \\
\multirow{2}{*}{ PDHB } & Endogenous ID & Yes & Yes & Yes & No \\
& Response to $\mathrm{H}_{2} \mathrm{O}_{2}$ & $\downarrow 33.9 \%$ & Trend $\uparrow$ & $\uparrow 1425 \%$ & $\mathrm{n} / \mathrm{a}$ \\
\hline
\end{tabular}
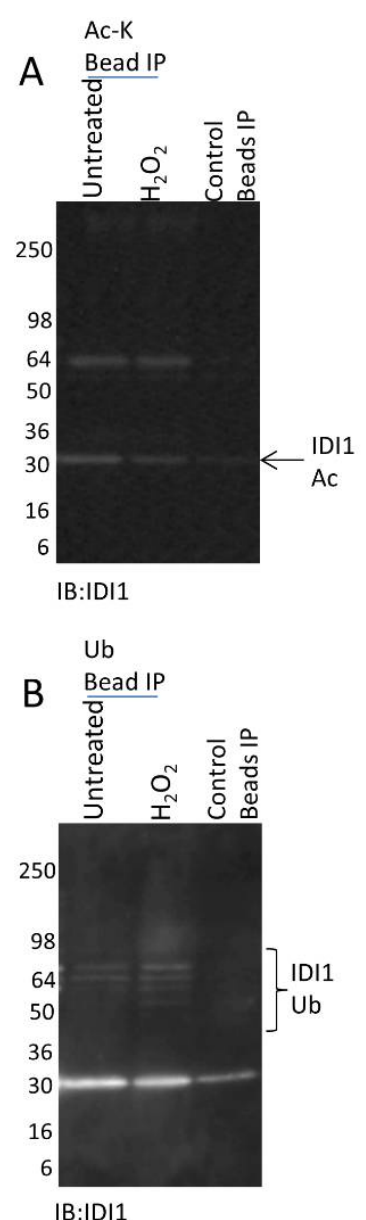

\section{SUMO $2 / 3$}

C Bead IP
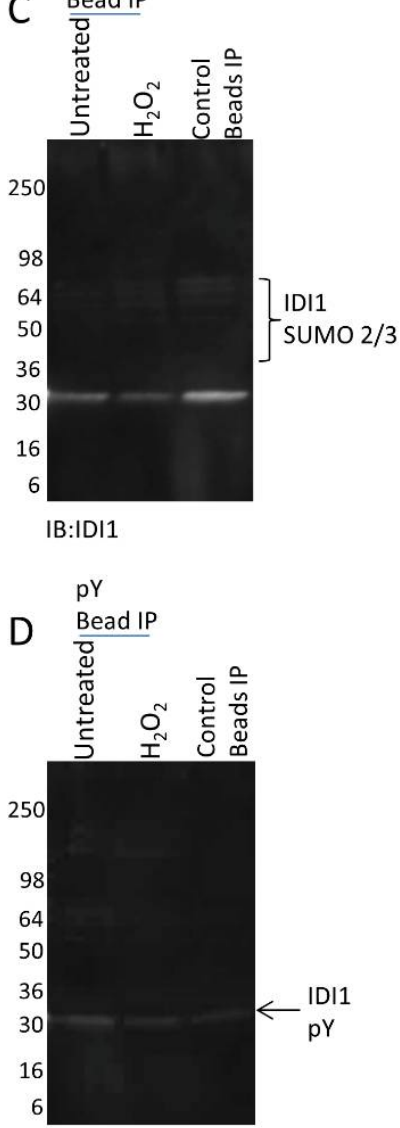

IB:IDI1

\section{E}

\section{IDI1 PTMs}

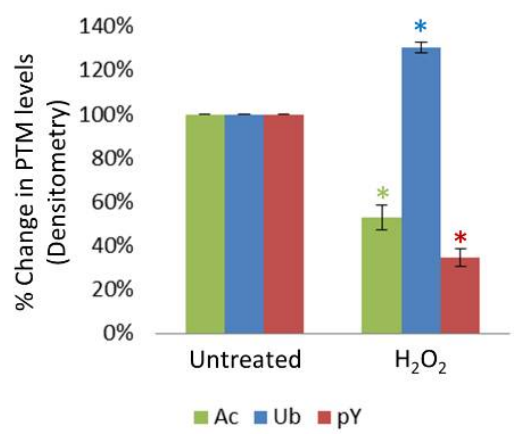

$\%$ of Total Protein Modified
\begin{tabular}{|l|c|c|}
\hline IDI1 & Untreated & $\mathrm{H}_{2} \mathrm{O}_{2}$ \\
\hline $\mathrm{Ac}$ & $0.596 \%$ & $0.312 \%$ \\
\hline Ub & $0.326 \%$ & $0.426 \%$ \\
\hline pY & $0.572 \%$ & $0.210 \%$ \\
\hline
\end{tabular}

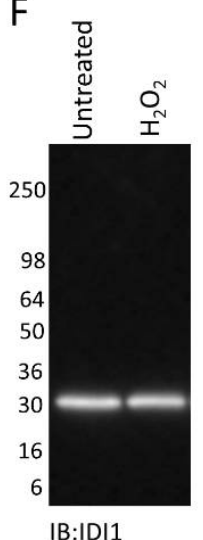

Figure 4. $\mathrm{H}_{2} \mathrm{O}_{2}$ induced Ac, Ub, SUMO 2/3, and pY modifications of IDI1. A431 cells either untreated or treated with $\mathrm{H}_{2} \mathrm{O}_{2}$ for $2 \mathrm{~h}$ were lysed with BlastR lysis buffer. Untreated and treated A431 lysates were incubated with (A) Ac-K beads to IP acetylated proteins and analyzed for acetylated IDI1, (B) Ub beads to IP ubiquitinated proteins and analyzed for ubiquitinated IDI1, (C) SUMO 2/3 beads to IP SUMOylated 2/3 proteins and analyzed for SUMO 2/3 modified IDI1, (D) and pY beads to IP tyrosine phosphorylated proteins and analyzed for tyrosine phosphorylated IDI1. All IPs were performed with appropriate control beads to detect non-specific detection. Shown are representative Westerns from $\mathrm{N} \geq 3$ independent experiments. (E) Quantification of background subtracted densitometric analysis of IDI1 PTMs. Error bars represent s.e.m. $t$-test statistical analysis was performed. ${ }^{*} p<0.05$. (F) WCL was analyzed for IDI1 levels. The percentage of PTM modified IdI1 relative to the total IDI1 levels for each modification is shown. 


\section{Discussion}

Common PTM crosstalk paradigms are beginning to emerge in the PTM field. For example phosphorylation has been shown to be a precursor to target protein $\mathrm{Ub}$ in several proteins $[46,47]$. Another pattern of PTM crosstalk exists between Ac and Ub where these modifications have been reported to compete to regulate the stability of the target protein $[48,49]$. Ac has been shown to stabilize target proteins [50], while poly-Ub is well-characterized as a mark for proteasomal degradation [5]. Both $\mathrm{Ac}$ and $\mathrm{Ub}$ primarily modify lysine residues, and many proteins have been identified that can be both acetylated and ubiquitinated on the same lysine residue [44], supporting the possibility of negative crosstalk between these PTMs.

Four mitochondrial proteins, PDHA1, IDI1, ATIC and PDHB were examined for potential crosstalk in this report. The activity of PDHA1 in regulating glucose homeostasis has previously been shown to be tightly regulated by PTM crosstalk, in particular between lysine acetylation (K321) and serine phosphorylation (S293) [29]. The data presented in this report supports a physiological role for PDHA1 acetylation as its endogenous Ac levels change in response to treatment with $\mathrm{H}_{2} \mathrm{O}_{2}$ (Figure 1D). Proteomic analysis has previously identified a single Ub modification (K385) on PDHA1 [51], we report an increase in ubiquitinated PDHA1 in response to $\mathrm{H}_{2} \mathrm{O}_{2}$ that suggests a physiological role for this PTM in regulating PDHA1 (Figure 2B). The opposing responses, 44\% increase in Ac and 53\% decrease in $\mathrm{Ub}$ of this target protein suggests that PTM crosstalk could be operating to regulate PDHA1 activity under the conditions described. Interestingly, the percent of PDHA1 that is acetylated $(6.1 \% \mathrm{UT}$ and $3.7 \%$ $\left.\mathrm{H}_{2} \mathrm{O}_{2}\right)$ is much higher than the percent of ubiquitinated protein $\left(0.13 \% \mathrm{UT}\right.$ and $\left.0.19 \% \mathrm{H}_{2} \mathrm{O}_{2}\right)$ suggesting that the PTMs are not quantitatively related; however, as there are 12 Ac lysines and only a single Ub lysine reported in the literature the exact quantitative relationship between these PTMs remains to be determined. The last point raises an important issue regarding the interpretation of pan IP enrichment data, if there are multiple copies of a given PTM on a target protein, a situation that is very common, then bona fide changes in PTM levels could be masked or underrepresented under some conditions, therefore identification of a PTM that does not show a change under the experimental conditions used should not automatically rule out a regulatory function. Better site-specific tools; for example, site specific antibodies would be beneficial when examining site-specific modifications physiologically.

Another target protein showing decreased Ac (47\%) and corresponding increases in Ub (30.3\%) was IDI1 (Figure 4A,B,E). Interestingly, this protein's PTM profile also indicated a dramatic reduction in phosphotyrosine (65.1\%) (Figure 4D,E). The available PTM data in the literature for this target is derived from MS analysis and shows that a single phosphotyrosine, four acetyl lysines and six ubiquitinated lysine residues have been identified in a variety of systems [44,51]. We report the first identification of temporal PTM changes in IDI1 which strongly suggests that IDI1 is regulated by PTMs and possibly involves PTM crosstalk. In this regard 3 of the 4 Ac sites and the $6 \mathrm{Ub}$ sites have been reported to occur on the same lysines (K113, K192 and K223) (phosphor site plus), making competitive crosstalk possible.

The two final target proteins selected for potential crosstalk analysis, ATIC and PDHB, both exhibited a similar PTM profile in that Ac decreases (22.8\% and 33.9\% respectively) while SUMO $2 / 3$ increases (36.9\% and $1425 \%$ respectively). As far as we are aware, this is the first report of either ATIC or PDHB being modified by SUMO 2/3 and it is the first report demonstrating opposing temporal changes between Ac and SUMOylation in either of these proteins. Crosstalk between SUMOylation (SUMO 1) and acetylation for the regulation of p53 has previously been reported [52], and a more recent paper describes wide ranging cross talk between SUMOylation and other PTMs, including Ac [53]. Follow-up studies are planned to define the physiologic role of SUMOylation, as well as the SUMO 2/3 and Ac crosstalk for ATIC and PDHB.

Throughout this study, we noted the relatively low stoichiometry of any given PTM. Ac was the most abundant PTM in all mitochondrial proteins in this study which may reflect the relatively large number of Ac modifications on each protein (Table 1). Low stoichiometry $(<1-5 \%)$ that translates to critical and regulated biological responses is a norm for PTMs and is one of the reasons that it 
is technically challenging to study these modifications [54-56]. The robust Signal-Seeker tools can detect PTMs as low as 11 molecules per cell [26], which is essential as many PTMs are highly dynamic. This may be particularly important for mitochondrial proteins as the stoichiometry of their PTMs appears to be quite low $[57,58]$. The ability to detect these small, but potentially meaningful changes are critical, as measuring endogenous changes of PTMs are necessary to understand the physiologic relevance of the modification.

PTM mechanisms continue to be identified as critical to the function of a rapidly growing number of proteins and pathways; it is important for non-PTM experts to have access to robust and simple tools that allow them to quickly and efficiently determine if PTMs are playing a role in the regulation of their protein/system of interest. We have validated a set of robust and simple tools that fulfill this need and should allow basic characterization of major PTMs to be a standard operation in any bio lab.

Supplementary Materials: The supplementary materials are available online at http:/ /www.mdpi.com/22277382/6/2/24/s1.

Author Contributions: H.H. conceived and performed experiments, and wrote the manuscript; A.L. conceived and performed experiments and provided reagents, expertise, and feedback; K.M. conceived experiments, wrote the manuscript, provided expertise and feedback, and secured funding.

Acknowledgments: This work was supported by funding from Cytoskeleton Inc.

Conflicts of Interest: H.H. and A.L. are employees of Cytoskeleton Inc.; K.M. is a founder of Cytoskeleton Inc. This work was supported by funding from Cytoskeleton Inc.

\section{References}

1. Seo, J.; Lee, K.J. Post-translational modifications and their biological functions: Proteomic analysis and systematic approaches. J. Biochem. Mol. Biol. 2004, 37, 35-44. [CrossRef] [PubMed]

2. Bah, A.; Forman-Kay, J.D. Modulation of Intrinsically Disordered Protein Function by Post-translational Modifications. J. Biol. Chem. 2016, 291, 6696-6705. [CrossRef] [PubMed]

3. Buuh, Z.Y.; Lyu, Z.; Wang, R.E. Interrogating the Roles of Post-Translational Modifications of Non-Histone Proteins. J. Med. Chem. 2018, 61, 3239-3252. [CrossRef] [PubMed]

4. Drazic, A.; Myklebust, L.M.; Ree, R.; Arnesen, T. The world of protein acetylation. Biochim. Biophys. Acta 2016, 1864, 1372-1401. [CrossRef] [PubMed]

5. Rape, M. Ubiquitylation at the crossroads of development and disease. Nat. Rev. Mol. Cell Biol. 2018, 19, 59-70. [CrossRef] [PubMed]

6. Wilson, V.G. Introduction to Sumoylation. Adv. Exp. Med. Biol. 2017, 963, 1-12. [CrossRef] [PubMed]

7. Hunter, T. The genesis of tyrosine phosphorylation. Cold Spring Harb. Perspect. Biol. 2014, 6, a020644. [CrossRef] [PubMed]

8. Basak, S.; Lu, C.; Basak, A. Post-Translational Protein Modifications of Rare and Unconventional Types: Implications in Functions and Diseases. Curr. Med. Chem. 2016, 23, 714-745. [CrossRef] [PubMed]

9. Olsen, J.V.; Mann, M. Status of large-scale analysis of post-translational modifications by mass spectrometry. Mol. Cell. Proteom. 2013, 12, 3444-3452. [CrossRef] [PubMed]

10. International Human Genome Sequencing Consortium. Finishing the euchromatic sequence of the human genome. Nature 2004, 431, 931-945. [CrossRef]

11. Jensen, O.N. Modification-specific proteomics: Characterization of post-translational modifications by mass spectrometry. Curr. Opin. Chem. Biol. 2004, 8, 33-41. [CrossRef] [PubMed]

12. Csizmok, V.; Forman-Kay, J.D. Complex regulatory mechanisms mediated by the interplay of multiple post-translational modifications. Curr. Opin. Struct. Biol. 2018, 48, 58-67. [CrossRef] [PubMed]

13. Venne, A.S.; Kollipara, L.; Zahedi, R.P. The next level of complexity: Crosstalk of posttranslational modifications. Proteomics 2014, 14, 513-524. [CrossRef] [PubMed]

14. Gu, B.; Zhu, W.G. Surf the post-translational modification network of p53 regulation. Int. J. Biol. Sci. 2012, 8, 672-684. [CrossRef] [PubMed]

15. Gadadhar, S.; Bodakuntla, S.; Natarajan, K.; Janke, C. The tubulin code at a glance. J. Cell. Sci. 2017, 130, 1347-1353. [CrossRef] [PubMed] 
16. Kontaxi, C.; Piccardo, P.; Gill, A.C. Lysine-Directed Post-translational Modifications of Tau Protein in Alzheimer's Disease and Related Tauopathies. Front. Mol. Biosci. 2017, 4, 56. [CrossRef] [PubMed]

17. Strahl, B.D.; Allis, C.D. The language of covalent histone modifications. Nature 2000, 403, 41-45. [CrossRef] [PubMed]

18. Luo, H.B.; Xia, Y.Y.; Shu, X.J.; Liu, Z.C.; Feng, Y.; Liu, X.H.; Yu, G.; Yin, G.; Xiong, Y.S.; Zeng, K.; et al. SUMOylation at K340 inhibits tau degradation through deregulating its phosphorylation and ubiquitination. Proc. Natl. Acad. Sci. USA 2014, 111, 16586-16591. [CrossRef] [PubMed]

19. Wang, Y.; Wang, Y.; Zhang, H.; Gao, Y.; Huang, C.; Zhou, A.; Zhou, Y.; Li, Y. Sequential posttranslational modifications regulate PKC degradation. Mol. Biol. Cell 2016, 27, 410-420. [CrossRef] [PubMed]

20. Cui, W.; Sun, M.; Zhang, S.; Shen, X.; Galeva, N.; Williams, T.D.; Staudinger, J.L. A SUMO-acetyl switch in PXR biology. Biochim. Biophys. Acta 2016, 1859, 1170-1182. [CrossRef] [PubMed]

21. Wang, X.; Li, D.; Wu, G.; Bazer, F.W. Functional Roles of Fructose: Crosstalk between O-Linked Glycosylation and Phosphorylation of Akt-TSC2-MTOR Cell Signaling Cascade in Ovine Trophectoderm Cells. Biol. Reprod. 2016, 95, 102. [CrossRef] [PubMed]

22. Francavilla, C.; Papetti, M.; Rigbolt, K.T.; Pedersen, A.K.; Sigurdsson, J.O.; Cazzamali, G.; Karemore, G.; Blagoev, B.; Olsen, J.V. Multilayered proteomics reveals molecular switches dictating ligand-dependent EGFR trafficking. Nat. Struct. Mol. Biol. 2016, 23, 608-618. [CrossRef] [PubMed]

23. Mertins, P.; Qiao, J.W.; Patel, J.; Udeshi, N.D.; Clauser, K.R.; Mani, D.R.; Burgess, M.W.; Gillette, M.A.; Jaffe, J.D.; Carr, S.A. Integrated proteomic analysis of post-translational modifications by serial enrichment. Nat. Methods 2013, 10, 634-637. [CrossRef] [PubMed]

24. Patrie, S.M. Top-Down Mass Spectrometry: Proteomics to Proteoforms. Adv. Exp. Med. Biol. 2016, 919, 171-200. [CrossRef] [PubMed]

25. Cai, W.; Tucholski, T.M.; Gregorich, Z.R.; Ge, Y. Top-down Proteomics: Technology Advancements and Applications to Heart Diseases. Expert Rev. Proteom. 2016, 13, 717-730. [CrossRef] [PubMed]

26. Horita, H.; Law, A.; Hong, S.; Middleton, K. A simple toolset to identify endogenous post-translational modifications for a target protein: A snapshot of the EGFR signaling pathway. Biosci. Rep. 2017. [CrossRef] [PubMed]

27. Horita, H.; Law, A.; Hong, S.; Middleton, K. Identifying Regulatory Posttranslational Modifications of PD-L1: A Focus on Monoubiquitinaton. Neoplasia 2017, 19, 346-353. [CrossRef] [PubMed]

28. Horita, H.; Law, A.; Middleton, K. Utilizing a Comprehensive Immunoprecipitation Enrichment System to Identify an Endogenous Post-translational Modification Profile for Target Proteins. J. Vis. Exp. 2018. [CrossRef] [PubMed]

29. Fan, J.; Shan, C.; Kang, H.B.; Elf, S.; Xie, J.; Tucker, M.; Gu, T.L.; Aguiar, M.; Lonning, S.; Chen, H.; et al. Tyr phosphorylation of PDP1 toggles recruitment between ACAT1 and SIRT3 to regulate the pyruvate dehydrogenase complex. Mol. Cell 2014, 53, 534-548. [CrossRef] [PubMed]

30. Lundby, A.; Lage, K.; Weinert, B.T.; Bekker-Jensen, D.B.; Secher, A.; Skovgaard, T.; Kelstrup, C.D.; Dmytriyev, A.; Choudhary, C.; Lundby, C.; et al. Proteomic analysis of lysine acetylation sites in rat tissues reveals organ specificity and subcellular patterns. Cell Rep. 2012, 2, 419-431. [CrossRef] [PubMed]

31. Baeza, J.; Smallegan, M.J.; Denu, J.M. Mechanisms and Dynamics of Protein Acetylation in Mitochondria. Trends Biochem. Sci. 2016, 41, 231-244. [CrossRef] [PubMed]

32. Dai, S.H.; Chen, T.; Wang, Y.H.; Zhu, J.; Luo, P.; Rao, W.; Yang, Y.F.; Fei, Z.; Jiang, X.F. Sirt3 attenuates hydrogen peroxide-induced oxidative stress through the preservation of mitochondrial function in HT22 cells. Int. J. Mol. Med. 2014, 34, 1159-1168. [CrossRef] [PubMed]

33. Ozden, O.; Park, S.H.; Wagner, B.A.; Song, H.Y.; Zhu, Y.; Vassilopoulos, A.; Jung, B.; Buettner, G.R.; Gius, D. SIRT3 deacetylates and increases pyruvate dehydrogenase activity in cancer cells. Free Radic. Biol. Med. 2014, 76, 163-172. [CrossRef] [PubMed]

34. Suzaki, Y.; Yoshizumi, M.; Kagami, S.; Koyama, A.H.; Taketani, Y.; Houchi, H.; Tsuchiya, K.; Takeda, E.; Tamaki, T. Hydrogen peroxide stimulates c-Src-mediated big mitogen-activated protein kinase 1 (BMK1) and the MEF2C signaling pathway in PC12 cells: Potential role in cell survival following oxidative insults. J. Biol. Chem. 2002, 277, 9614-9621. [CrossRef] [PubMed]

35. Calvo, S.E.; Clauser, K.R.; Mootha, V.K. MitoCarta2.0: An updated inventory of mammalian mitochondrial proteins. Nucleic Acids Res. 2016, 44, D1251-D1257. [CrossRef] [PubMed] 
36. Takakubo, F.; Cartwright, P.; Hoogenraad, N.; Thorburn, D.R.; Collins, F.; Lithgow, T.; Dahl, H.H. An amino acid substitution in the pyruvate dehydrogenase E1 alpha gene, affecting mitochondrial import of the precursor protein. Am. J. Hum. Genet. 1995, 57, 772-780. [PubMed]

37. Song, H.; Komuniecki, R. Novel regulation of pyruvate dehydrogenase phosphatase purified from anaerobic muscle mitochondria of the adult parasitic nematode, Ascaris suum. J. Biol. Chem. 1994, 269, 31573-31578. [PubMed]

38. Richter, U.; Lahtinen, T.; Marttinen, P.; Suomi, F.; Battersby, B.J. Quality control of mitochondrial protein synthesis is required for membrane integrity and cell fitness. J. Cell. Biol. 2015, 211, 373-389. [CrossRef] [PubMed]

39. Williamson, J.; Petralia, R.S.; Wang, Y.X.; Mattson, M.P.; Yao, P.J. Purine Biosynthesis Enzymes in Hippocampal Neurons. Neuromol. Med. 2017, 19, 518-524. [CrossRef] [PubMed]

40. Manandhar, G.; Miranda-Vizuete, A.; Pedrajas, J.R.; Krause, W.J.; Zimmerman, S.; Sutovsky, M.; Sutovsky, P. Peroxiredoxin 2 and peroxidase enzymatic activity of mammalian spermatozoa. Biol. Reprod. 2009, 80, 1168-1177. [CrossRef] [PubMed]

41. Tan, K.; Fujimoto, M.; Takii, R.; Takaki, E.; Hayashida, N.; Nakai, A. Mitochondrial SSBP1 protects cells from proteotoxic stresses by potentiating stress-induced HSF1 transcriptional activity. Nat. Commun. 2015, 6, 6580. [CrossRef] [PubMed]

42. Hou, X.; Liu, Y.; Liu, H.; Chen, X.; Liu, M.; Che, H.; Guo, F.; Wang, C.; Zhang, D.; Wu, J.; Chen, X. PERK silence inhibits glioma cell growth under low glucose stress by blockage of p-AKT and subsequent HK2's mitochondria translocation. Sci. Rep. 2015, 5, 9065. [CrossRef] [PubMed]

43. Arrabal, S.; Lucena, M.A.; Canduela, M.J.; Ramos-Uriarte, A.; Rivera, P.; Serrano, A.; Pavón, F.J.; Decara, J.; Vargas, A.; Baixeras, E.; et al. Pharmacological Blockade of Cannabinoid CB1 Receptors in Diet-Induced Obesity Regulates Mitochondrial Dihydrolipoamide Dehydrogenase in Muscle. PLoS ONE 2015, 10, e0145244. [CrossRef] [PubMed]

44. Hornbeck, P.V.; Zhang, B.; Murray, B.; Kornhauser, J.M.; Latham, V.; Skrzypek, E. PhosphoSitePlus, 2014: Mutations, PTMs and recalibrations. Nucleic Acids Res. 2015, 43, D512-D520. [CrossRef] [PubMed]

45. Parmigiani, R.B.; Xu, W.S.; Venta-Perez, G.; Erdjument-Bromage, H.; Yaneva, M.; Tempst, P.; Marks, P.A. HDAC6 is a specific deacetylase of peroxiredoxins and is involved in redox regulation. Proc. Natl. Acad. Sci. USA 2008, 105, 9633-9638. [CrossRef] [PubMed]

46. Swaney, D.L.; Beltrao, P.; Starita, L.; Guo, A.; Rush, J.; Fields, S.; Krogan, N.J.; Villén, J. Global analysis of phosphorylation and ubiquitylation cross-talk in protein degradation. Nat. Methods 2013, 10, 676-682. [CrossRef] [PubMed]

47. Filipcik, P.; Curry, J.R.; Mace, P.D. When Worlds Collide-Mechanisms at the Interface between Phosphorylation and Ubiquitination. J. Mol. Biol. 2017, 429, 1097-1113. [CrossRef] [PubMed]

48. Ryder, D.J.; Judge, S.M.; Beharry, A.W.; Farnsworth, C.L.; Silva, J.C.; Judge, A.R. Identification of the Acetylation and Ubiquitin-Modified Proteome during the Progression of Skeletal Muscle Atrophy. PLoS ONE 2015, 10, e0136247. [CrossRef] [PubMed]

49. Butler, P.L.; Staruschenko, A.; Snyder, P.M. Acetylation stimulates the epithelial sodium channel by reducing its ubiquitination and degradation. J. Biol. Chem. 2015, 290, 12497-12503. [CrossRef] [PubMed]

50. Giandomenico, V.; Simonsson, M.; Gronroos, E.; Ericsson, J. Coactivator-dependent acetylation stabilizes members of the SREBP family of transcription factors. Mol. Cell. Biol. 2003, 23, 2587-2599. [CrossRef] [PubMed]

51. Wagner, S.A.; Beli, P.; Weinert, B.T.; Schölz, C.; Kelstrup, C.D.; Young, C.; Nielsen, M.L.; Olsen, J.V.; Brakebusch, C.; Choudhary, C. Proteomic analyses reveal divergent ubiquitylation site patterns in murine tissues. Mol. Cell Proteom. 2012, 11, 1578-1585. [CrossRef] [PubMed]

52. Wu, S.Y.; Chiang, C.M. Crosstalk between sumoylation and acetylation regulates p53-dependent chromatin transcription and DNA binding. EMBO J. 2009, 28, 1246-1259. [CrossRef] [PubMed]

53. Hendriks, I.A.; Lyon, D.; Young, C.; Jensen, L.J.; Vertegaal, A.C.; Nielsen, M.L. Site-specific mapping of the human SUMO proteome reveals co-modification with phosphorylation. Nat. Struct. Mol. Biol. 2017, 24, 325-336. [CrossRef] [PubMed]

54. Johnson, H.; Eyers, C.E. Analysis of post-translational modifications by LC-MS/MS. Methods Mol. Biol. 2010, 658, 93-108. [CrossRef] 
55. Wu, R.; Haas, W.; Dephoure, N.; Huttlin, E.L.; Zhai, B.; Sowa, M.E.; Gygi, S.P. A large-scale method to measure absolute protein phosphorylation stoichiometries. Nat. Methods 2011, 8, 677-683. [CrossRef] [PubMed]

56. Ordureau, A.; Munch, C.; Harper, J.W. Quantifying ubiquitin signaling. Mol. Cell 2015, 58, 660-676. [CrossRef] [PubMed]

57. Weinert, B.T.; Iesmantavicius, V.; Moustafa, T.; Schölz, C.; Wagner, S.A.; Magnes, C.; Zechner, R.; Choudhary, C. Acetylation dynamics and stoichiometry in Saccharomyces cerevisiae. Mol. Syst. Biol. 2015, 11, 833. [CrossRef] [PubMed]

58. Weinert, B.T.; Moustafa, T.; Iesmantavicius, V.; Zechner, R.; Choudhary, C. Analysis of acetylation stoichiometry suggests that SIRT3 repairs nonenzymatic acetylation lesions. EMBO J. 2015, 34, 2620-2632. [CrossRef] [PubMed]

(C) 2018 by the authors. Licensee MDPI, Basel, Switzerland. This article is an open access article distributed under the terms and conditions of the Creative Commons Attribution (CC BY) license (http://creativecommons.org/licenses/by/4.0/). 